\title{
Service Learning Pitfalls: Problems You Didn't See Coming
}

Emily Lane Morin, Texas A\&M University-Kingsville, USA

\begin{abstract}
This study examines a semester-long service learning course. The purpose of this study is to determine the factors that were responsible for the successes and failures of the projects. There is a profusion of literature that underscores the positive aspects of service learning. However, literature is scarce on why service learning may not always be the best option and how even the most thought out plans can go awry. The goal of this study is to use the unsuccessful aspects of the service learning course as a learning tool. By diagnosing the problems that occurred during the semester, the author seeks to contribute to solving them in the future, making the next service learning course a successful one. The information in this study will help make other instructors more aware of the issues that can arise while teaching a service learning course. This will enable instructors to plan accordingly and conduct a successful service learning course.
\end{abstract}

Keywords: service learning, challenges, student teacher dynamic, non-profit organizations, communication.

\section{INTRODUCTION}

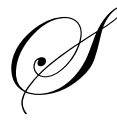

ervice learning courses are being implemented more frequently as university faculties strive to find better ways to increase student learning and retention. Dr. Ashley Bennington of Texas A\&M UniversityKingsville (TAMUK), a veteran service learning course instructor, decided to implement a service learning course into the Business Communications class she taught.

Bennington hoped to offer the business students at TAMUK a richer, more beneficial learning experience to help them in their future careers. The service learning course was offered to upper level business majors in the spring 2008 semester. During the course, students encountered many issues that set back the learning process. The failures of the class far outweighed the successes. Success in the case of the class Bennington taught would entail more than just a passing grade. The student would leave the classroom with practical knowledge, hands-on experience, and an ability to implement all of the skills the class was designed to teach.

\section{REVIEW OF LITERATURE}

To answer the research question, this study examines the current literature defining service learning and identifying what makes a service learning course successful. It will also examine obstacles to anticipate when trying to implement a service learning course. According to Timmermans and Bouman (2004), service learning is a combination of "program, philosophy, and pedagogy" (pg. 92). According to the Learn and Serve America's National Service Learning Clearing House (n.d.), "Service-learning is a teaching and learning strategy that integrates meaningful community service with instruction and reflection to enrich the learning experience, teach civic responsibility, and strengthen communities." When implemented successfully, students have the opportunity to learn how to function outside of the classroom and put theory into practice, gaining "real world" experience (McEachern, 2001).

McKay and Estrella (2008) explore how a service learning course can have a positive impact on retention and student engagement; they find that academic and social integration are key factors to engagement and can significantly predict the retention of students. Lopez and Lee (2005) give a summary of the many positive aspects of service learning. Some of the benefits include: facilitating active, experiential learning, fostering problem 
solving, critical thinking, communication and teamwork skills, adding realism to the classroom and increasing the motivation of the students due to the possibility of their work being implemented.

The benefits of using a service learning course are easily seen, but how does one make the class successful? Lopez and Lee (2005) provide principles to help facilitate service learning courses when dealing with clients and client-based projects. They emphasize that selecting the client with care may be the most important action of all. Clients have a direct impact on the students regarding what they will learn during the course. Clients should be recruited and then carefully selected. The screening of a potential client must be taken very seriously. Ways that a client can contribute to the failure of a client-based project is by expecting too much from the student, becoming over or under involved, and by having a lack of serious respect for the project or what the student/teacher is trying to accomplish.

Lopez and Lee (2005) feel that nonprofit organizations make "particularly good" clients because of the student exposure to alternative business philosophies and marketing methods, the ability to build money-managing skills when working with a small budget, the facilitation of reciprocal learning due to the volunteers having only novice skills or a lack of marketing training, and the chance for the student to work on a project that they may have a vested personal interest in. Lopez and Lee see students having a chance to teach as well as be taught.

Not everyone agrees that non-profit organizations make the best clients. When is a nonprofit organization a liability to the service learning course? According to McEachern (2001), the very nature of nonprofit organizations can be a source of problems. The make-up of a non-profit organization can be a significant factor in whether or not the student can accomplish what they set out to do.

Individuals with "mixed skill" levels can mean that the student will spend time teaching the people they work with business communication skills or computer skills (McEachern, 2001). In the wrong situation, the student will spend more time teaching and less time learning. Time can be lost while trying to teach a volunteer or member of the organization skills that the student already knows.

Non-profit organizations are often understaffed or made up of volunteers (McEachern, 2001). The volunteers many have many other obligations that are a higher priority than the volunteer organization. If the organization is unable to afford secretarial help, they may rely on electronic means of contact. The student may find him or herself unable to reach vital representatives, unable to do the research necessary to completing the project, or find themselves without proper guidance.

Another factor that must be considered is the student. While outside factors can certainly impact the success or failure of a student's project, the student's attitude can be the deciding factor. Some students will come into the class expecting to do "volunteer work" or are only looking to build up their résumé (Jones, 2002). The level of maturity a student possesses can also determine how a student will handle the responsibilities of a service learning course. It can never be forgotten that students are an unpredictable variable. Instructors must be ready for unexpected situations and sometimes even unanswerable questions. Students that are expected to work together can run into many different situations. Differences in background and values can impact the group's ability to work together.

\section{BACKGROUND}

Dr. Ashley Bennington has been a professor at TAMUK for six years. Prior to this, Bennington taught at St. Edwards University for two years. During her teaching at St. Edwards, Bennington used service learning in the classroom. Bennington's experiences with service learning at St. Edwards were positive. Bennington felt that she would have the same results when service learning was introduced to her class at TAMUK.

The class observed and researched was BCOM 3304-001. This class was modified to implement service learning into the business communication curriculum. Bennington was awarded a grant to reformat the class to include the service learning portion. Bennington was also allowed to choose an assistant. The assistant chosen was a journalism student who had worked with Bennington in a similar capacity in previous semesters. The researcher 
served as the assistant and was responsible for recording grades, keeping track of attendance, and offering tutoring services in writing and proofreading.

The business communication class is a required class for all business majors at TAMUK. Only juniors or seniors were allowed to register for this class due to it being a pilot program. Twenty-two students registered for the course, and by the end of the year, twenty students remained. The majority of the students were business majors. The other students were agricultural business majors.

The BCOM class was split into two parts. The beginning of the course was designed to help students improve their writing and learn to produce business communications such as letters or memos containing requests, denials, and adjustment messages. Students were also instructed on writing agendas and meeting minutes.

After the initial business writing was completed, students were given the guidelines of the service learning project that they would be taking part in. Students were asked to break up into groups of four or five. Students were asked to go out into the community and find a non-profit organization to work with. The students were to act as independent communication consultants.

Students were then to meet with the organization's leaders and find a communication issue that needed to be addressed. Once they found an issue, students were to write a proposal to the client outlining what service they would like to provide for the organization. The course was not about doing community service in the traditional sense. Students were not supposed to stuff envelopes or lick stamps. Students would be acting as professionals that would be contracted to solve a problem within the organization.

Once the student's proposal was accepted by the client, the student group was responsible for meeting weekly to do research on the organization's problem. For example, one student group was responsible for working with Keep Kingsville Beautiful (KKB). The communication issue that they addressed was the organization's inability to get people interested in the program. The student group researched how the organization was currently advertising. The group then researched the most effective methods of advertising. With this information, the group was able to determine that the pamphlet KKB had been using was outdated. Researched had proved that the use of color in brochures piqued interested and was more successful than the black and white the organization had been using.

After the client accepted the proposal, each group was responsible for doing the background research necessary to support their recommendations. After research was completed, student groups were responsible for presenting their findings in a business report. The report was also orally presented to the client and the class. Then the final report was submitted to the instructor and the client.

Students were expected to document their progress throughout the class by submitting their group meeting agendas and a copy of their group meeting minutes. Through this, the instructor could keep tabs on what was going on in the groups and see what progress was being made.

To successfully complete the course, students had to follow this process throughout the class. Some of the expected student learner outcomes were for the student to learn how to do research and how to put their research into a business report. Examples of agendas, meeting minutes and a business report were contained in the student's textbook.

During the spring 2008 semester, Bennington had three other classes. They were BCOM classes and were taught without the service learning element. These classes were also required to write a business research report. Students in the other three classes were also tutored and mentored by the researcher and it was noted that the other classes did not report having the difficulty the service learning course had. 


\section{METHODOLOGY}

The nature of the research done is qualitative. Data collected comes in the form of personal experience with the students and professor involved in the class through face-to-face interaction, personal interviews and an informal electronic interview questionnaire given to some of the students. Three students were initially interviewed after the class project was finished. The students were asked for their viewpoints about what they learned in the class, what they liked/disliked in the class, what they felt could be improved, how they felt about the teacher throughout the semester, and how they felt about the project itself and working with a group.

Students were encouraged to give any information they felt was relative and were assured that none of the information would affect their final grade or be made known to the professor before the class was finished. Students were made to understand that their responses would be used as data for a research project and they would remain anonymous when quoted.

The questionnaire was developed after the personal interviews were conducted. At that time, the researcher noticed trends in what information the students wanted to impart to the interviewer. The questionnaire was a series of open-ended questions that covered five topics. Five students filled out the electronic questionnaire.

The first topic asked students general questions about the class and how they felt about it throughout the semester. Students were asked why they had taken the class, how did they feel about the assignments, if the assignments helpful, and did they feel they had learned anything.

The second topic covered was group work. Students were asked how they felt about working with a group at different times during the semester, how they felt about the project, what issues they experienced in the group and what percentage was accomplished by the student being interviewed. Students were also asked for recommendations regarding group work and whether they felt Bennington should have chosen the groups.

The third topic concerned how the students felt about the instructor. Students were asked to explain how they felt about the instructor personally, about the instructor's teaching style, and what the professor could have done to improve the class.

The next topic involves the student's personal schedule. Students were asked to give an estimate of how many classes they were taking, how much time was spent at an outside job, how much time was spent performing extracurricular activities, homework, and how much time was spent with family/friends. Students were also asked to describe what sort of worker they were.

The last topic asked for any general recommendations the student had for the class. Students could add any information that they felt the questionnaire had not covered. The number of students who answered the questionnaire represented only a portion of the information used.

Other information was obtained based on what the researcher observed during the course. During the semester, the researcher was able to attend the majority of the classes the students attended. The researcher observed the professor instructing the class and watched the class provide feedback. The researcher also took notes about what was taught and what assignments were due.

Because of this, the researcher was able to get to know the students personally and observe how they functioned in the classroom setting. The researcher was also able to observe the teacher/student dynamic. There were many instances in which the researcher, acting as a teaching assistant, was able to tutor and sometimes mentor the students. Frequently throughout the semester, students would come into the researcher's office and speak about their experiences in the class. Because of this, the researcher was able to identify many of the issues that were affecting the student's learning experience. This also ensured the researcher had contact with all the students in the class. Information given informally was collected and noted for future use. 
The researcher often spent time with the instructor speaking about the concerns students had brought to the researcher's attention. The instructor was also asked to fill out a questionnaire providing details about what the instructor felt was learned by herself and by her students. The instructor was asked why she decided to introduce service learning into her course and what was done to prepare for the implementation of the service learning portion of the class. The instructor was also asked what she would have done differently to improve the class.

\section{FINDINGS}

The students interviewed were asked why they took the class. Half of the students answered that they took the class because it was a required class or because "it was the only BCOM [class] open when I registered." This seemed to be the general trend in the class. During the course of the semester, other students in the classroom affirmed that this was the main reason they were taking the class. A small number responded that they were actually interested in being involved in a service learning course.

Student expectations were mixed. Some students looked forward to the class and looked forward to working with clients to receive real-life experience. Many students felt very confident that they would be able to handle the class. Other students felt it would be "difficult and challenging from hearsay." Yet other students felt that it was going to be "easy because it was the first time she was going to try something new."

Students also had mixed expectations regarding the professor. Some students came into the classroom with preconceived notions. There were students that had heard that Bennington was a tough teacher and expected a lot from students. After the students started the class, many had a positive attitude toward the class and the work that was going to be involved. One student went as far as to say that Bennington was "motivational."

Working in groups was a major part of the class. About half the work involved in the course required a group effort. The group dynamic had a lot to do with successes and failures. Issues that the students reported dealing with are:

1. Schedule conflicts due to jobs, families, class, home, or extracurricular activities

2. Partners who did not fulfill their part of the work

3. Issues dealing with contacting and/or meeting with the clients

4. Communication issues with the professor

5. Communication issues with fellow classmates.

Students were asked if they felt that issue one — schedule conflicts — could have been dealt with by having the professor choose the groups according to proximity to each other and by daily schedules. Some students answered that they felt this would have been a good idea. Others felt that they would rather choose their own group members because they were all adults capable of making their own decisions. Another student felt that choosing group members was a better idea because most people had already worked with some of the students before and had an idea about the quality of work they would produce.

Interviewed students were asked to report how their time was spent during the week. The majority of the students interviewed reported working up to 40 hours a week or more. Many of the students were also taking a full load of classes, anywhere from 12 to 15 hours a week. Homework and extracurricular activities took up space in a student's schedule. Some students in the class were parents and reported child-care took up a lot of their free time.

Communication issues were experienced by student and professor alike. Students interviewed often felt that communicating with a group of three or four was difficult. This was directly impacted by the personal schedules of each student. The majority of students interviewed, or spoken personally with, complained that schedules just did not match, making it difficult to meet or even speak on the phone. Another issue was meeting with the clients. Students often spoke of how hard it was to reach the client on the phone or through e-mail. When they were able to achieve this, meetings were hard to schedule because the client often had their own busy schedule and could not accommodate the student's needs. Groups often had to split up tasks and have only part of the group meet with the client. 
Students also cited having trouble understanding the due dates of the assignments. A schedule of assignment due dates was given out to the students in the beginning of the class. Due dates were changed during the course of the semester to accommodate the students who were having trouble meeting with each other or clients. Students were also given extensions to finish or redo work when necessary.

Teacher/student communication as an issue came up frequently throughout the semester. Students had trouble understanding what was expected of them and how to accomplish certain tasks. The professor was forced to deal with students that did not have the skills necessary to accomplish certain vital tasks for the project. The majority of students spoke out about the professor at different times. Students admitted to feeling frustrated with the professor, their groups, and the project in general. Many felt that it was unprofessional of the professor to communicate her frustration and disappointment with the class's progress. Students were disappointed at times when their work did not meet with the instructor's approval.

Other students felt the professor worked hard to help the student's succeed. One interviewed student felt that the professor was very helpful in analyzing the problems within a group and was sympathetic and helpful. Another student felt that working with her personally was beneficial and helped the group solve issues they had.

Students had a lot to say about working in groups, and communicating with each other. Groups made of perfect strangers were able to come together and work amiably and accomplish their tasks. One group made up of students that had prior dealings with each other had to be split up because two of the members were not pulling their weight. Another student who filled out a questionnaire wrote that he had violent feelings towards one of his group members, admitting to wanting to "beat a group member" due to his "comments and attitude."

Students were often afraid to speak to the professor about other group members. Because of this, students often came to the researcher for aid and to act as a go-between. Students were often worried that their grade would be hurt because of other group members' careless attitude toward the project. Students reported group members not showing up for meetings, not turning in their part of the work, or not showing up for class. During the semester, one group lost two members because the students were dropped for lack of attendance. One unexpected issue that was related to the researcher was another student having difficulty working with a student due to his personal hygiene. This was an issue that definitely was not expected but still had to be addressed by the professor.

Students interviewed were asked to give an estimate regarding how much work the student and their classmates accomplished out of $100 \%$. For example, a student in a group of four would have reported he or she had done $25 \%$ of the work if all four members had done an equal amount of work. After comparing the estimates given and the work the researcher saw students do in class, the researcher feels that the students were honest in their estimations. The estimates often show one student doing the majority of the work.

One group was split from four members into two members. It was close to the end of the semester and the two students had a lot of work to catch up on. Both group members were interviewed and filled out questionnaires. Group member A felt that she had done $99 \%$ of the work alone. Group member B admitted that group member A did about $90 \%$ of the work. Group member B admitted that this project would not have been accomplished if group member A had not done the majority of the work. Group member B felt that it would have been detrimental to the project if too many new ideas were introduced so late and had to be content with Group Member A taking control of the project.

In another group, one member out of five was reported to have done $60 \%$ of the work. The other members did from $5 \%$ to $12.5 \%$ of the work. The interviewed student gave credit to another group member for having done the majority of the work and reported that their personal contribution was about $12.5 \%$.

By the end of the class, most students professed their relief at seeing the project finished, for better or worse. Despite how students felt about the class as a whole, the majority of the students interviewed or spoken with personally said they felt good about the work they had done, regardless of the grade they received. Some students felt a sense of pride and accomplishment regarding what they had done for their organization. 
Other students communicated their frustrations with the class. Students often said that they felt ill-prepared for a class of this caliber. Students who were not informed as to the nature of the class did not know they would be working with the community or be doing so much work on their own. Many students said this was the first time they had done work of this nature.

Interviewed students were asked to give recommendations regarding how to improve the class. Students responded with many different answers. Some felt that smaller groups would have made the projects easier. Others felt that it was too much work for just one class and that splitting the class into two semesters would have made the work load easier to handle. Choosing group members and clients for the groups was another recommendation. One student felt that the client should have a part in the grading process.

According to the responses of students in personal communications through interaction outside the classroom or interviewed responses, most students felt that the class did have something to offer to students. Students felt that working with a client was a great experience.

One student made his ire known at the end of the class and admitted to feeling angry, disappointed and felt the class was a waste of time. Two months later, the very same student stopped by the researcher's office to admit that the skills learned in the class had helped him in a recent job situation. The student's attitude was totally changed after that.

The reason the instructor gave for wanting to implement service learning into the classroom was to provide a "more engaging experience for students" and to "help connect the College of Business to the community." The instructor reviewed materials from her teaching at St. Edwards and reviewed her teaching curriculum for the BCOM class to prepare for the service learning course.

The instructor felt that the students did not fully understand the research process - an important part of the class. While the instructor was aware that many of the students were happy with the work they had produced and the service they had done, the instructor was not pleased with their learning experience. According to the questionnaire, Bennington felt that students were more focused on the activities involved i.e. meetings, presentations instead of the basic research that needed to be done to complete the report.

The instructor felt that more vigilant monitoring of the student's progress was needed. The instructor felt that the client variable was much more distracting to the students. More supervision is something the instructor felt should be used in future classes. The instructor also mentioned feeling out of touch with the students.

\section{DISCUSSION}

Based on the information gathered during the semester, the students of the service learning course experienced difficulties in three areas. Communication issues seemed to impact the progress of the students the most during the semester. Scheduling conflicts were mentioned frequently during interviews and during informal visits to the researcher's office. The level of experience that the student's held and their expectations regarding the class was also an issue.

The first area to be discussed will be the area of communication. Students felt that communication issues were the most problematic. Students experienced communication issues with their fellow students, the teacher, and the client. Students were expected to set up meetings to work on their projects. Class time was allotted to the students but some work was expected to be done outside the classroom. One student felt that reaching a consensus was difficult. Another student felt that time constraints meant that the project could not be explored as fully as the student felt it should have.

Communication between the client and student was a problem at times. This was a major frustration for students. Students often worried that their grade was going to be impacted when they were unable to complete an assignment due to the client not having time to meet with the class group. Those who are looking to implement a service learning course into their curriculum should make sure to allot time for this kind of situation. Clients should 
also be made to understand how important this project is. A visit with the client, teacher, and student group is highly recommended. This gives the professor a chance to view the client and evaluate how seriously the client will take the project.

Student-to-student communication is not as easily solved. In this case, it is up to the students to choose people that they will be able to work with. Students also need to be made to understand that they are responsible for communicating with their fellow students.

Communication between teacher and student is another aspect that is very important to the classroom dynamic. In this course, many students were unhappy with the communication skills of the professor. Often the class fell apart when faced with so many students having problems with their projects. In retrospect, it seems that the best way to deal with this would be to schedule more reflection time and time for face-to-face meetings with the professor. Most students felt that the professor was very helpful when she advised them outside of the classroom. With a classroom of twenty students, it can be inferred that some students had trouble getting the attention they needed. Advice given to one group would not necessarily have been helpful for another.

Scheduling conflicts will always be a problem for a project of this type. Students have to learn to coordinate their schedules and prioritize their tasks. In this area, communication is also key to the success or failure of a group. Being able to sit down and figure out a schedule that works for everyone is vital to the group's success. In this case, it might be best for the professor to evaluate the student's schedules and have a hand in picking group members. Time spent in class reviewing where the students are from, what days they are at the school, and what kind of activities take up their days would help students find group members that have free time similar to their own.

Based on the research done for this study, the researcher questions whether or not the students were mature enough for a class of this caliber. Students often complained that they had never experienced working on their own. Many students also said they had not known they would be required to know how to write agendas, meeting minutes or a business report. These were key elements to the class. Students were supposed to conduct meetings in which an agenda had been sent out prior to the meeting. Students were also expected to record meeting minutes. These were to be turned for the professor to keep track of what the students were doing during their group meetings.

The instructor expected the students to have experience with these types of assignments. While teaching at St. Edwards, Bennington did not have this problem. Being out of touch with what the student body knows and what they have been taught was another issue that worked against student and professor alike.

At this time, Bennington has met with Joseph Villarreal and given him copies of what the students will be expected to know when they reach her class. Villarreal teaches an introductory business class that incoming students are required to take. By providing Villarreal with an example of the work students will be expected to know, Villarreal can expose his students to the course content they will be expected to know before they reach her class. This is an alternative to splitting the class into two courses and teaching the business communication portion separate from the service learning portion. In this course, you cannot do one without the other.

The expectations of the professor were not met during this course. Many of the students were unable to work together and groups had to be broken up. The main assignment, a written business report to be turned in to the organization, was not understood by many of the students. Presentations to the client were also a part of the experiential learning; however, some groups never presented to the client.

It should be mentioned that while the failures seemed to outweigh the successes of this classroom experience, one cannot forget the major accomplishment that did occur. The majority of the students did feel that they had accomplished something and saw the benefit in working with the community. The issue seems to be that students felt this class was geared toward community service and were quick to forget the research portion of the class. Many of the students spoke of how they enjoyed working with the clients and serving the community. From a student perspective, this is a very important learning experience. 


\section{CONCLUSION}

This study was just a brief look into the service learning dynamic. The researcher felt it was important to report class issues because there is not enough literature detailing the issues an instructor can face when trying to implement a service learning course. During the research phase of this study, it was found that the majority of articles on service learning dealt only with the benefits and positive aspects of service learning.

More research needs to be conducted on service learning and the experiences of students and instructors. This study is limited because there was no quantitative data used in determining trends within the study. The study is also limited because there was not a control group. Out of the five groups that started the class, only one group fully succeeded in meeting all their goals. A long-term study of whether or not the students used what they learned in the future would shed some light as to whether or not the class was benefited the students. This research would help determine what the service learning experience truly taught the students, or it would determine if it was just a "waste of time" as some of the students felt it was.

\section{AUTHOR INFORMATION}

Emily Lane Morin is a senior journalism student at Texas A\&M University-Kingsville. Morin is an honors student and a member of the Alpha Chi honor's society. She is a reporter and writes for the school newspaper, The South Texan. Morin has also been published in TAMUK's literary magazine Writer's Bloc. Morin has worked as a teaching assistant for Dr. Bennington for two years. Tutoring in writing and grammar as well as proofreading are services Morin provides to students having trouble with their writing assignments.

\section{REFERENCES}

1. Frazer, L., Raasch, M., Pertzborn, D., \& Bradley, F. (2007). The impact of community clients on student learning: The case of a university service-learning course. Journal of Experiential Education 29(3), 407412.

2. Ikeda, E. (2001). Additional Resources. New Directions for Higher Education, 114, 97-100.

3. Jones, S. (2002). The underside of service learning. About Campus, September-October 2002, 10-15.

4. Learn and Serve America. (n.d.). National Service Learning Clearing House. Retrieved September 28, 2008, from http://servicelearning.org/what is_service-learning/service-learning_is/index.php

5. Lopez, T.B., \& Lee, R.G. (2005). Five principles for workable client-based projects: Lessons from the trenches. Journal of Marketing Education, 27(2), 172-188.

6. McEachern, R. (2001). Problems in service learning and technical/professional writing: Incorporating the perspective of nonprofit management. Technical Communication Quarterly, 10(2), 211-224.

7. McKay, V. \& Estrella, J. (2008). First-generation student success: The role of faculty interaction in service learning courses. Communication Education, 57(3), 356-372.

8. Timmermans, S.R. \& Bouman, J.P. (2004). Seven ways of teaching and learning: University-community partnerships at baccalaureate institutions. Journal of Community Practice, 12(3/4), 89-101. 


\section{NOTES}

